\title{
O Atendimento Psicológico a Adultos e Idosos com Quadros Psicossomáticos no Pronto-Socorro de um Hospital
}

\author{
The Psychological Care for Adults and Elderly with Psychosomatic Frames in the \\ Emergency Room of a Hospital \\ La Atención Psicológica para los Adultos y Ancianos con Marcos Psicosomáticos en la \\ Sala de Emergencia de un Hospital
}

\author{
Alessandra Da Rocha Arrais \\ Ana Paula Da Silva Vasques Oliveira \\ Flora Teixeira Mota de Paula \\ Universidade Católica de Brasília
}

\begin{abstract}
Resumo
O presente estudo refere-se à atuação psicológica no pronto-socorro de um hospital particular de Brasília. Objetivouse estudar os aspectos psicossomáticos dos pacientes adultos e idosos que chegaram ao hospital durante o primeiro semestre de 2011. O método utilizado foi o clínico-qualitativo, que se baseou nas informações coletadas durante as rondas de estimulação e nos atendimentos psicológicos aos pacientes. Procedeu-se a análise do discurso e foi confirmado que fatores psicossomáticos influenciam na instalação e manutenção da doença. A exteriorização de conteúdos somatizados colaborou para aliviar o sofrimento e melhorar a qualidade de vida desses pacientes, e ressaltou a importância da presença do psicólogo na equipe multidisciplinar.

Palavras-chave: Psicossomática; Pronto-Socorro; Psicologia Hospitalar e da Saúde.
\end{abstract}

\begin{abstract}
The present study refers to the psychological performance in emergency room of a private hospital in Brasilia. The objective was to study the psychosomatic aspects of adults and elderly patients who arrived at the hospital during the first half of 2011. The method used was the clinical and qualitative, which was based on the information collected during the rounds of stimulation and on psychological care to patients. The analysis of speech was made and it confirmed that psychosomatic factors influence the installation and maintenance of the disease. The externalization of somatized content collaborated to relieve suffering and improve quality of life of these patients, and emphasized the importance of the presence of the psychologist in the multidisciplinary team. Keywords: Psychosomatics; Emergency Department; Health Psychology.
\end{abstract}

\section{Resumen}

El presente estudio se refiere a la actuación psicológica en la sala de emergencias de un hospital privado en Brasilia. Se planteó como objetivo estudiar los aspectos psicosomáticos de los pacientes adultos y ancianos que llegaron al hospital durante el primer semestre de 2011. El método utilizado fue el clínicocualitativo, que se basa en la información recogida durante las rondas de la estimulación y atención psicológica a los pacientes. Se procedió analizar el discurso de los pacientes y se confirmó que los factores psicosomáticos influyeron en la instalación y el mantenimiento de la enfermedad. La externalización de los contenidos sumados contribuyó para aliviar el sufrimiento y mejorar la calidad de vida de estos pacientes, además de que se destacó la importancia de la presencia del psicólogo en el equipo multidisciplinario. Palabras clave: Psicosomático; Sala de emergencia; Psicología de la Salud.

\section{Introdução}

Existe uma tendência a pensarmos que somos compostos por duas partes distintas: de um lado o corpo, de outro a mente, como se uma não tivesse muita ligação com a outra. Da mesma forma, há uma tendência em dividirem-se as doenças em físicas e psíquicas, como se fossem de naturezas diferentes. Entretanto, na realidade, esta divisão não existe. Somos indivíduos inteiros, não podemos nos ver enquanto partes separadas, pois mente e corpo, saúde e doença, físico e mental, são todas partes de uma mesma engrenagem (Castro; Andrade; Muller, 2006). Se tivermos um problema físico de saúde, como uma dor na coluna, por exemplo, isso tem influências no nosso humor e comportamento. A tensão emocional vem junto com uma tensão física e posso ficar com os músculos rígidos. Isso pode gerar dor, que gera alteração de humor, que gera mais dor, criando um ciclo interminável!

Portanto, existe toda uma rede de comunicação interna e externa, em que cada sentimento, sensação ou emoção é comunicado, traduzido e expresso de uma determinada forma, por todos os elementos envolvidos (Spinelli, 2010). Infelizmente, na cultura biomédica em que ainda vivemos, desqualificamos sobremaneira nossos sentimentos e não lhe damos a devida atenção e tratamento. Assim, problemas emocionais normalmente se tornam crônicos, e muitos vão acabar batendo a porta dos inúmeros Prontos-Socorros existentes. 
A grande questão atual é que, apesar de sabida a inter-relação entre somático e psíquico, temos poucas oportunidades de acessar os aspectos mais subjetivos de nossas experiências cotidianas. Vivemos atualmente de forma acelerada, o que repercute na questão da escuta. "Os profissionais não têm mais tempo para se dedicar à escuta dos doentes" (Marco, 2003, p. 59). Perdeu-se o interesse pela observação e história da pessoa, tanto no plano do desenvolvimento físico, como no plano psicológico e social, e a investigação se restringe ao problema atual, à sintomatologia física e, particularmente, ligada à especialidade de cada profissional.

Barros (2002) afirma que sempre existem aspectos psicológicos e subjetivos que acompanham, em menor ou maior grau, qualquer doença, e não necessariamente dão origem a elas. Embora muitos profissionais admitam que existam componentes de ordem subjetiva ou afetiva, mesmo em doenças em que as evidencias orgânicas sejam mais explícitas, frequentemente, os profissionais não se sentem preparados para lidar com esse tipo de fenômeno humano.

Filho (2005) garante que toda doença é psicossomática, e que a divisão das doenças em físicas e mentais é um equívoco, pois todas as doenças orgânicas sofrem influência da mente de quem as apresenta, assim como as doenças mentais podem ser traduzidas em processos bioquímicos, e vice-versa. Em outras palavras, Spinelli (2010) também assegura que cada doença é psicossomática, visto que os fatores emocionais influenciam todos os processos do corpo e que os fenômenos somáticos e psicológicos ocorrem no mesmo organismo e são apenas dois aspectos do mesmo processo. Pacheco (1994) alega que quando há algum problema em nossa vida emocional, alguma alteração orgânica pode surgir. Tendo sanado o problema psíquico, o problema orgânico também poderá ser eliminado.

Marco (2003) salienta ainda que, embora os instrumentos e a tecnologia proporcionem uma maior facilidade e segurança no diagnóstico de doenças, o próprio profissional deveria ser o principal "instrumento" quando se trata de contato humano. Infelizmente, muitos profissionais, ainda hoje, têm uma concepção da doença puramente física. Não sentem a necessidade de informar-se sobre a situação afetiva/subjetiva do paciente “... porque, do seu ponto de vista, não fazem parte da doença, embora ele pudesse reconhecer que fazem parte do doente" (Casseto, 2004, p. 153).

E nesse árido cenário, surge a figura do psicólogo da saúde, oferecendo-se para escutar o sujeito que está doente a falar sobre si, ou qualquer coisa que queira dizer, tendo como objetivo dar voz à subjetividade do sujeito (Simonetti, 2009). Seu objetivo é buscar, por meio da palavra, uma forma de enfrentamento da situação emergencial, pelo paciente. O psicólogo da saúde possibilita a verbalização dos conteúdos emocionais, fazendo emergir os aspectos subjetivos tanto do doente como dos seus acompanhantes.

Simonetti (2009) afirma que “... a conversa que o psicólogo proporciona ao paciente não é uma conversa comum" (p. 24), o psicólogo permite que o paciente fale sobre suas angústias, podendo simbolizá-las e dissolvê-las. A maioria dos outros profissionais, a família e os amigos do paciente, muitas vezes não o permitem viver seus sentimentos. Buscam encobrir a angústia, destruí-la ou negá-la. Na medida em que o paciente fala com o psicólogo, pode reconhecer a possibilidade de participação ativa no tratamento da enfermidade física/psíquica, juntamente com a equipe, em um movimento de cura pessoal.

Diante da necessidade do paciente em ser ouvido e da ética médica em atuar sobre o sintoma, surge o espaço para a psicologia da saúde. Nesse sentido, é perceptível que as diferentes circunstâncias, nas quais o sintoma orgânico aponta para o adoecimento psíquico, provocam angústia no corpo médico da instituição, que, tocado em seu saber, abre espaço para a intervenção do psicólogo. Assim, a divisão entre corpo e mente cria a possibilidade, ou até mesmo a necessidade de ação do psicólogo, pois o que se espera desse profissional é que possa tomar o corpo como algo não separado do aspecto psíquico (Moretto, 2001).

A psicologia da saúde é um campo de atuação da saúde mental, não tratando apenas de doenças com causas psíquicas e psicossomáticas, mas de aspectos psicológicos de qualquer doença. A inserção do psicólogo no contexto hospitalar inclui uma extensa área de atuação. Segundo Chiattone (2000), para atuar no hospital, o psicólogo inicialmente "emprestou" recursos técnicos e metodológicos de outras áreas do saber psicológico. Entretanto, esse conhecimento se mostrou inadequado a esse contexto, cuja especificidade tem exigido a construção de um novo saber e a adequação de técnicas.

Dentre os setores pertinentes à atuação do psicólogo da saúde, estão a UTI, as enfermarias, a internação e o pronto-socorro. Especificamente, o pronto-socorro (PS) é o local destinado ao tratamento das emergências médicas, tendo em vista que essas emergências são situações clínicas onde os pacientes se encontram em risco, o que requer um tratamento imediato (Simonetti, 2009). Portanto, um dos objetivos do PS é a normalização das funções vitais, bem como amenizar a dor dos pacientes. Já a cura completa da doença e/ou o tratamento de aspectos psicológicos são considerados relevantes, porém, devem estar em segundo plano (Simonetti, 2009).

Romano (1999) e Simonetti (2009) apontam que o PS perdeu seu caráter de atendimento de unidade de emergência, passando a ter uso inadequado pela população que o procura, assumindo o status de "sala de espera de todos os problemas sociais" (Romano, 
1999, p.52).

$\mathrm{O}$ atendimento no PS se dá de forma emergencial e urgente, conforme a conceituação e etiologia das palavras, ambas derivadas do latim, sendo emergentia uma situação considerada crítica, ligada à emergência médica, e urgentia significando um caso ou situação de emergência. Portanto, os atendimentos realizados no PS estão sempre sujeitos às situações inesperadas, podendo ocorrer comprometimentos em diversos âmbitos da vida dos pacientes (Angerami-Camon, 1998).

O paciente em situação de emergência traz consigo elementos latentes carregados de simbolismo, para os quais o psicólogo tem papel fundamental na oferta da escuta, possibilitando a exteriorização das palavras, visando o enfrentamento por parte do paciente e dos familiares, da situação emergencial (Romano, 1999; Simonetti, 2009). Sendo assim, o PS é um setor que não atende apenas emergências médicas, mas também diversos problemas de nível biopsicossocial, o que torna necessária a atuação diferenciada do psicólogo, no sentido de estar preparado para lidar não somente com a dimensão psíquica, mas também a social.

A intervenção do psicólogo da saúde, especificamente no PS, visa minimizar o sofrimento e compreender os fatores relacionados ao adoecimento físico e/ou psíquico responsáveis pela procura ao hospital, no que diz respeito aos pacientes, e suporte psicológico aos familiares e acompanhantes. Pode ter caráter preventivo, o que exige desvendar os significados subjetivos e individuais que as experiências de doença e hospitalização têm para o indivíduo (Chiattone, 2000).

Dessa maneira, a abordagem do psicólogo no PS é imprescindível, entretanto deve seguir o fluxo de atendimento. Ou seja, nesse setor, em princípio, os pacientes recorrem a atendimento médico. No entanto, isso não equivale à ausência de conflitos psíquicos relacionados à situação de adoecimento. Do ponto de vista psicológico, as situações de emergência se caracterizam por uma série de desordens físicas e psíquicas, onde o paciente demonstra sensações intensas, algumas vezes reprimidas, não encontrando meios eficazes de simbolizar a situação de adoecimento como maneira de enfrentamento.

Angerami-Camon, psicólogo da saúde, fala sobre a psicossomática de forma bastante clara em um texto:

"Se você o tempo todo mostra ao mundo que tudo, absolutamente tudo, sempre está bem... que as coisas nunca te abalam ou te preocupam... Saiba que o corpo irá te desmentir... As enxaquecas, gastrites, inflamações na garganta, entre outras manifestações, são severos sinais da farsa que você está fazendo da própria vida. Não adianta tentar colocar um sorriso no rosto se o coração está sangrando... a alma não tolera essa farsa... o corpo irá gritar com os mais variados sintomas... o mioma, o cálculo renal, a taquicardia, infecção urinária sempre são sinais de alerta (...)" [sic] (Angerami-
Camon, 2001, p. 301).

O objetivo do presente trabalho foi investigar a presença dos fatores psicológicos em pacientes que chegam ao PS de um hospital particular do DF. Desta forma, relataremos e analisaremos algumas situações que ocorreram no PS, em que percebemos a importância dos aspectos psicológicos no processo de adoecimento.

Esperamos que este trabalho possa embasar melhor a prática do psicólogo da saúde em um PS, assim como colaborar para desmitificar o PS e ressaltar que este é também, um espaço para a psicologia e para a subjetividade.

\section{Diagnóstico do Pronto-Socorro}

Os dados contidos neste trabalho foram obtidos por meio de: observações; informações da Gerente Administrativa, da Gerente Técnica e outros membros da equipe de saúde do pronto-socorro do referido hospital de Brasília; e escuta dos pacientes. O objetivo é relatar nossas impressões com a finalidade de nos ambientarmos no setor e na rotina do PS.

A entrada do PS do hospital é a única via de acesso tanto para os atendimentos de emergência como a qualquer procedimento oferecido pela instituição (consultas médicas, internações eletivas, visitas, UTI, exames laboratoriais e radiológicos, atendimentos burocráticos, etc). Como todo PS, possui suas peculiaridades, momentos críticos e tumultuados, intercalados de momentos mais tranquilos.

Durante o nosso trabalho, realizado em um período de cinco meses, observamos a dinâmica do funcionamento, o fluxo de pessoas que circulam no setor (funcionários, pacientes, familiares $\mathrm{e}$ visitantes) e as dificuldades inerentes ao próprio serviço emergencial. Tivemos acesso a vários pacientes, familiares e cuidadores. Procuramos estabelecer o rapport, por meio da ronda, na intenção de procedermos, quando possível, a alguns breves exames do estado psíquico. Ouvimosm as dificuldades, angústias, medos e expectativas dos pacientes e acompanhantes, visando proporcionar um melhor acolhimento, na tentativa de tornar a estadia hospitalar uma experiência menos traumática.

\section{Ambientação}

A estrutura física do pronto-socorro é composta por três boxes: um box pediátrico composto por 5 leitos; um box masculino e um box feminino, ambos compostos por 6 leitos, cada. Devido à demanda, muitas vezes é necessário à internação de mulheres no boxe masculino.

No hall central existem seis consultórios médicos que atendem as seguintes especialidades: Pediatria, Cardiologia, Cirurgia Geral, Ortopedia e Traumatologia e Clínica Médica (2 consultórios). Há também um box exclusivo para emergências cardiológicas, com equipamentos de reanimação, 
monitorização e exames, tendo capacidade de atender apenas um paciente por vez. Existe ainda um espaço para descanso e repouso médico.

No momento de chegada ao hospital, o paciente retira uma senha, senta-se na sala de espera e aguarda o sinal da sua vez. No entanto, alguns pacientes e acompanhantes relataram que existe uma demora de aproximadamente 25 minutos entre a sua chegada e as chamadas para o preenchimento da guia de atendimento, provocando angústia e ansiedade, descaracterizando assim o sentido da palavra "urgência" inerente a um PS.

\section{Equipe do PS}

A equipe do pronto-socorro é dividida em administrativa e técnica. A primeira possui duas auxiliares de faturamento que trabalham oito horas diárias de segunda a sexta-feira, três recepcionistas diurnas e duas noturnas. A gerente do setor tem carga horária de 40 horas semanais.

A equipe técnica de enfermagem é composta por uma enfermeira chefe, um enfermeiro supervisor e quatro auxiliares de enfermagem durante todos os dias, sendo nos finais de semana e feriados composta por três auxiliares e um enfermeiro supervisor responsável por todos os setores do hospital. Muitos trabalham na escala de 12/36 horas.

Ressalta-se que não temos conhecimento se o número de funcionários lotados nestes setores é suficiente para dar suporte a toda demanda do trabalho, como orienta o COREN. No entanto, somos sabedores que a saúde do trabalhador é a mola propulsora para um bom andamento do serviço. Trabalhar com restrições no número de funcionários, num ambiente sobrecarregado, além de não ser salutar para a equipe, compromete toda a qualidade do atendimento.

\section{Rotina do setor}

Após passagem pela recepção, os pacientes são encaminhados para o hall de espera e suas fichas são depositadas nos caixotes fixos nas portas dos consultórios. Os médicos de cada especialidade atendem os pacientes, de acordo com a ordem das fichas depositadas no caixote de sua porta. Ao término da consulta, se houver necessidade, os pacientes são encaminhados para os primeiros cuidados, realização de exames e medicações específicas, geralmente, endovenosas. De acordo com a regra do hospital, o paciente só pode ficar internado na enfermaria do PS por, no máximo, 24 horas.

Observamos também que quando há solicitação de um exame laboratorial ou radiológico, o paciente fica, muitas vezes, um longo período aguardando a realização e o resultado dos exames, até a nova espera para outro atendimento com o médico assistente. Segundo informações de alguns pacientes, não há prioridade nos pedidos de urgência, em detrimento dos exames marcados eletivamente. Ou seja, em uma consulta que seria de emergência, o paciente aguarda tanto quanto uma consulta eletiva, causando estresse e mal estar nos pacientes pelo arrastamento do seu sofrimento devido à demora nos atendimentos. Fato também comunicado à Gerente Administrativa, pela equipe de psicologia, a fim de verificar a procedência das reclamações.

\section{Principais patologias atendidas no PS}

As principais patologias identificadas nos pacientes do Pronto-Socorro foram: gastroenterocolite aguda; rotavírus; hipertensão arterial crônica; doenças cardíacas e respiratórias; distúrbios endócrinos (diabete, tireoidite); e sintomas diversos (cefaléia, dores abdominais, náuseas, dores no corpo, mal estar, etc.).

Diante da patologia do paciente, buscamos colher algumas informações quanto à sua reincidência, adesão ao tratamento, prevenção, alguma situação de estresse desencadeante, como ele e/ou acompanhante está lidando com o momento de hospitalização, quem compõe a sua rede de apoio e se está bem informado sobre seu quadro clínico, além de esclarecimentos que possam minimizar os males envolvidos na possível internação.

\section{Método}

O presente trabalho foi realizado utilizando-se o método clínico-qualitativo, por se tratar de uma pesquisa aplicada ao setting dos cuidados com a saúde (Turato, 2000). O método clínico-qualitativo aglutina, de um lado, as concepções epistemológicas dos métodos qualitativos de pesquisa, desenvolvidos a partir das ciências humanas e, de outro lado, os conhecimentos e atitudes clínico-psicológicos desenvolvidos tanto no enfoque psicodinâmico das relações pessoais, como, historicamente, no campo da prática da medicina clínica (Turato, 2000). A metodologia qualitativa utilizada foi o estudo de caso, por se tratar de uma “... inquirição empírica que investiga um fenômeno contemporâneo dentro de um contexto da vida real, quando a fronteira entre o fenômeno e o contexto não é claramente evidente e onde múltiplas fontes de evidência são utilizadas" (Yin, 1989, p. 23).

Os participantes da pesquisa foram 10 pacientes adultos e idosos, sendo um homem e nove mulheres, atendidos no pronto-socorro de um hospital particular em Brasília, no período entre fevereiro e junho de 2011, e que apresentaram sintomas psicossomáticos.

A coleta de dados foi realizada nas rondas e nos atendimentos psicológicos prestados aos pacientes, no pronto-socorro. Para analisar os dados obtidos, foi utilizada a análise de discurso, pois, de acordo com Mutti e Caregnato (2006), a análise de discurso considera a língua, história e sujeito; trabalha com o sentido e não com o conteúdo do texto, em que o 
discurso produzido pela fala sempre terá relação com o contexto sócio histórico.

$\mathrm{Na}$ análise de discurso não se tem a pretensão de dizer o que é certo, porque isso não está em julgamento. Porém, o analista é um intérprete, que faz uma leitura influenciada pelo seu afeto, sua posição, suas crenças, suas experiências e vivências, sendo a interpretação sempre passível de equívoco (Mutti; Caregnato, 2006).

\section{Resultados e Discussão}

A partir dos resultados e dados investigados, algumas questões serão discutidas, tendo em vista as intervenções realizadas no PS e a revisão de literatura levantada para esse trabalho.

Confirmando Moretto (2001), ficou notável a necessidade do paciente em ser ouvido, ou seja, a escuta proporcionada pelo psicólogo possibilitou aos indivíduos expressar suas angústias e sentimentos. É perceptível também que, em circunstâncias diversas, o adoecimento psíquico provoca angústia na equipe de saúde da instituição, o que oportuniza a possibilidade de intervenção do psicólogo.

Em relação à atuação do psicólogo nos diversos setores e não somente no PS, as enfermidades oferecem certo nível de adoecimento psíquico, o que possibilita, como parte do tratamento dos pacientes, o trabalho de acolhimento e intervenção, por meio de técnicas psicológicas pertinentes ao âmbito hospitalar. Tais técnicas visam minimizar a ansiedade do paciente frente à situação de adoecimento e potencializar a sua adesão ao tratamento. Nessa perspectiva e de acordo com a proposição de Chiattone (2000), a intervenção psicológica no PS tem como foco o sofrimento, no que diz respeito à compreensão dos fatores relacionados ao adoecimento físico e/ou psíquico, que motivou a busca pelo atendimento no hospital.

De modo geral, chamou nossa atenção que foram encontrados no PS muitos casos de pacientes com sintomas psicossomáticos. Uma das pacientes que adentrou o pronto-socorro, tinha 67 anos e chegou com um queixa aparentemente física de arritmia e falta de ar, após algum tempo de atendimento, contou sobre o sofrimento que viveu em seu casamento, durante 42 anos, com um marido alcoolista, que não era fiel e a submetia a situações constrangedoras e estressantes com frequência. Esta paciente chegou a afirmar "meu marido maltratou tanto o meu coração, que hoje ele quase não funciona mais". Este pode ser um exemplo da origem psicológica de determinadas doenças orgânicas.

Outra paciente, de 55 anos de idade, chegou ao PS com fortes dores abdominais. Após exames que descartaram a possibilidade de apendicite ou complicações renais, ao longo do acompanhamento psicológico, revelou que seu único filho estava saindo de casa e que ela passaria a morar sozinha, em breve.
A dor abdominal pôde então ser compreendida como a dor do parto, significando a sensação de ninho vazio, causada pela saída do filho da casa da mãe. Tal sentimento não pôde ser expresso porque foi utilizada a racionalização de que a saída do filho seria um passo importante para o mesmo. A simples expressão verbal do sentimento de tristeza foi importante para o controle da dor abdominal. Apesar de saber que este passo era importante para o filho, a mãe compreendeu que, ainda assim, tinha o direito de sentir a sua falta.

Um exemplo de sintoma atenuado pela fala foi o caso de uma paciente idosa, de 65 anos, que chegou ao PS sem conseguir emitir movimentos com o braço e a mão direita. Durante o atendimento, a mesma revelou que durante o fim de semana, a pessoa que cuidou de seu lar durante mais de vinte anos anunciou que não iria mais trabalhar em sua residência. Esta pessoa tomava conta de todas as questões relacionadas ao apartamento, como limpar, lavar e passar roupas, cozinhar, lavar louça, fazer compras e pagar contas. A paciente afirmou que estava perdendo o seu "braço direito". Após o atendimento, e a oportunidade de colocar em palavras o seu sofrimento, a paciente conseguiu retomar alguns movimentos, reavendo o controle sobre a movimentação do braço.

Uma paciente chegou ao PS com infecção urinária. Após a investigação do caso, percebeu-se que se tratava de uma pessoa jovem, de 29 anos, que havia se mudado para Brasília a trabalho, deixado a família, os amigos e o namorado. Trabalhava no período noturno, entretanto, participava de reuniões no horário comercial. A paciente dormia cerca de quatro horas por dia e não tinha tempo para uma alimentação regular e saudável. Seu nível de estresse estava tão elevado, que a mesma precisou de uma doença física, que a acometesse, para que o seu corpo pudesse parála e mostrar-lhe que esse ritmo não era saudável e que precisava rever sua vida.

Esse caso ilustra bem o que Filho quis dizer com a frase "... a fuga de dificuldades econômico-sociais para um leito hospitalar, problemas psicossomáticos vários não resolvidos... Portanto uma parte da população de nossos hospitais gerais é fatalmente composta por pacientes com grandes sofrimentos psíquicos" (Filho, 2005, p. 121).

O luto não elaborado também pode causar sintomas psicossomáticos. Uma paciente, de 30 anos, certa vez, chegou ao PS do hospital com o diagnóstico de tontura e hipertensão. Ela estava grávida de cinco meses. Diante do histórico e investigação do caso, a paciente revelou que havia vivenciado uma situação de aborto, aos cinco meses de gestação, ocorrida há dois anos e que era uma gravidez extremamente desejada e planejada. Naquele dia, a paciente estava completando cinco meses de uma nova gravidez, e provavelmente temia vivenciar a perda de um filho novamente. $\mathrm{O}$ fato de ter sua dor legitimada em atendimento colaborou consideravelmente para o 
controle de sua ansiedade e pressão arterial. Havia uma angústia que a consumiu durante todo o dia, e que foi compreendida e nomeada no atendimento psicológico.

Uma jovem paciente, 28 anos, chegou ao PS com o quadro de vômitos e forte angústia. Relatou que havia se mudado para Brasília junto com o marido e deixado em sua cidade todos os amigos e familiares. Ao chegar à cidade, o esposo não permitiu que a mesma procurasse um emprego em sua área de atuação, afirmando que ela deveria passar em um concurso público para ganhar dinheiro e ajudar nas despesas de casa. A paciente não se sentia dona do apartamento em que morava e nem dona das próprias decisões, já que não podia viajar, trabalhar ou comprar o que quisesse. Seu marido tinha o dinheiro e, portanto, o poder de decisão sobre como gastá-lo. A paciente estava vivendo uma situação muito difícil de digerir e este sofrimento se manifestou em seu sistema digestivo. Apesar de sua situação indicar a necessidade de um acompanhamento psicológico e psiquiátrico, devido à intensidade dos sintomas, uma simples "conversa" com a psicóloga foi importante para diminuir a sua angústia e permitir que os remédios administrados surtissem efeito.

Esse caso ilustra bem, do ponto de vista psicológico, que as situações de emergência se caracterizam por uma série de desordens físicas e psíquicas, onde o paciente demonstra sensações intensas, algumas vezes reprimidas, não encontrando meios eficazes de simbolizar a situação de adoecimento como maneira de enfrentamento (Spinelli, 2010).

Para Romano (1999), os conflitos familiares acabam interferindo no processo de cura do paciente. Quando estes sentem que são rejeitados ou não se sentem acolhidos e amados, podem não aderir ao tratamento, comprometendo, assim, a evolução do quadro de adoecimento.

Uma senhora de 60 anos, procurou o PS com quadro de cefaléia intensa. Relatou que, para ela, trabalhar estava sendo insuportável. O trabalho trazia um sofrimento profundo, pois recentemente, sua melhor amiga, que trabalhava na mesa ao seu lado, havia falecido em um acidente de trânsito. Todos os dias, ao olhar para o lado, esta senhora sentia uma falta enorme da companheira de longos anos, que dividia com ela um cigarro durante os intervalos. Desde então, era frequente para ela faltar ao trabalho e, como justificativa, apresentava um atestado médico, com algum CID referente à doença física. Parece que, muitas vezes, nossas "dores subjetivas" só são consideradas realidade quando são visíveis, concretas, intensas, como se não pudessem ser validadas socialmente (Angerami-Camon, 2001).

Assim as emoções e sentimentos vão tentar encontrar um canal de expressão muitas vezes via corpo, de um jeito mais concreto e perceptível (Spinelli, 2010). Em outras palavras, às vezes, se torna necessário que a emoção se manifeste através do corpo, para poder ser atendida e considerada (Angerami-Camon, 2001). Muitas vezes não conseguimos relacionar nossas dores no corpo com nosso estado emocional, porque é mais difícil perceber a ligação de uma coisa com outra.

Em outro caso, uma paciente de 26 anos, chegou ao hospital com a queixa de uma cefaléia persistente, que já perdurava há 35 dias e não cessava nem com os mais fortes analgésicos. Após a internação da paciente e realização de vários atendimentos e exames, a mesma relatou várias situações vivenciadas como abandono do pai, abuso sexual, uso de drogas ilícitas, relação conflitiva com a mãe, relacionamento violento com o marido e a sogra, entre outros sofrimentos que não cessavam nem com o mais forte analgésico.

Entendemos que a paciente havia guardado tantos sofrimentos, que a sua dor precisou se manifestar fisicamente, para que ela fosse encarada, e não mais reprimida "embaixo de uma pedra", onde ela dizia que colocava seus problemas. Da mesma forma que a paciente "colocava seus problemas embaixo de uma pedra", a mesma estava sentindo como se sua cabeça estivesse nesse mesmo local. Pareceu mais aliviada após o atendimento e, como a paciente tinha muitas demandas psicológicas, recebeu um encaminhamento para atendimento psicoterápico.

Um senhor, 70 anos, chegou ao pronto-socorro, apresentando vários episódios de vômitos. Relatou que seu neto mais velho estava aprendendo a pegar ônibus para voltar da escola para casa e que, recentemente, tinha se perdido, o que o deixou muito angustiado e desesperado, até que finalmente o encontrou. Afirmou ter tido esses mesmos sintomas há aproximadamente um ano atrás e que tinha acontecido algo similar, que também o preocupou muito. Disse que iria observar mais como reagia a situações parecidas e como, de certa forma, seu corpo respondia a questões de ordem emocional, já que não foi constatado nada biológico através dos exames.

Em certo atendimento, uma jovem paciente de PS, 25 anos, que havia perdido o seu bebê pelo fato deste ter-se enrolado ao cordão umbilical já aos oito meses de gestação, afirmou que nunca havia conversado com alguém sobre a morte do filho (e isso já havia ocorrido há cinco meses). E foi no PS que ela pôde falar e vivenciar este luto e despedir-se do filho que partiu. Essas lágrimas presas há tanto tempo lhe tirou um peso das costas e a fez compreender que falar sobre isso podia diminuir a sua tristeza. Ser acolhida, ouvida e ter seus sentimentos validados a ajudou a fazer novos planos para sua vida, entre eles, procurar uma terapia.

Enfim, estes são apenas alguns exemplos dos vários casos psicossomáticos que adentraram $\mathrm{o}$ PS durante o período de cinco meses, mas que se apresentaram encobertos por sintomatologia física. Muitas vezes, nem a equipe de saúde e nem o próprio 
paciente conseguem relacionar as suas dores no corpo com o estado emocional. Às vezes é tão difícil e sofrido ter que se dar conta de certas emoções e sentimentos que "não percebê-los" é a maneira que encontramos como sendo aparentemente mais fácil de lidar como o que nos incomoda. Assim, cuida-se do orgânico e silencia-se o psíquico.

As dificuldades emocionais normalmente se tornam crônicas, mas mesmo assim, as pessoas ainda resistem em procurar ajuda especializada. Desqualificam muito seus sentimentos e não lhes dão a devida atenção e tratamento. Porém, quanto mais se resiste em reconhecer as dificuldades emocionais, e em mudar seus hábitos, e até seus valores, maior é o sofrimento e o adoecimento (Angerami-Camon, 2001).

A doença física é legitimada em nossa sociedade, já as questões de ordem emocional são vistas, muitas vezes, como "frescura". Ninguém falta um dia no emprego porque está triste (a não ser em caso de luto pela perda de algum parente), porém, é comum pessoas faltarem o emprego por sentirem-se mal fisicamente.

Não estamos desvalorizando a questão orgânica, mas tentando fazer uma comparação para mostrar o quanto as questões emocionais são desvalorizadas. As pessoas podem faltar ao trabalho se estiverem com uma dor de garganta incômoda, mas não se estiverem esgotadas psicologicamente. Talvez por este motivo, deixamos passar as nossas questões psicológicas, até que estas questões se revelem em nosso corpo. Neste momento, precisamos ir ao hospital cuidar da saúde física, sem notar que os aspectos psicológicos podem ter colaborado para o adoecimento.

Pacheco (1994) afirma que ainda não foram descobertos a causa psíquica e o método de tratamento do estresse, porém, sua incidência aumenta a cada ano. A tendência tem sido colocar a culpa em questões ambientais como o trabalho em excesso, casamentos fracassados ou trânsito intenso, porém, pesquisas comprovam que existem pessoas que se queixam mais do estresse nas férias do que em períodos de trabalho, assim como habitantes de cidades pequenas que apresentam grande número de sintomas psicossomáticos.

Não é raro encontrarmos nos hospitais, pacientes cujo objetivo não seja viver, mas sim morrer. Alguns pacientes param de se alimentar para alcançar este fim. É um pedido de ajuda, uma forma de demonstrar sua tristeza, sua angústia e sua dor. Para Simonetti (2009) existem dois tipos de sujeito, o sujeito na urgência (aquele que se torna o foco das atenções terapêuticas por se encontrar em risco) e o sujeito da urgência (aquele que demanda atendimento em caráter de urgência), embora as duas situações possam se concentrar em um mesmo indivíduo. Estes pacientes que param de alimentar-se são sujeitos da urgência. Muitas crises diminuem quando as angústias são contidas e o paciente se sente cuidado, daí a importância da psicologia atuar no ambiente hospitalar, especialmente em um setor de prontoatendimento (Angerami-Camon, 1988).

Percebemos a importância do trabalho da psicologia, que, ao contrário dos outros profissionais que tentam muitas vezes calar esse grito de socorro, busca fazer com que este grito seja ouvido. Dizemos aos pacientes: Fale! Permita-se viver esse momento de tristeza! Nós nos permitimos viver momentos felizes, mas por que não nos permitimos viver os momentos tristes? A dor faz parte da vida da mesma maneira que a alegria. Sufocar esta dor é o mesmo que intensificála ou somatizá-la.

Ao falar de sua dor, o paciente adulto ou idoso, aprende a reconhecê-la, dimensioná-la e a lidar com ela (Angerami-Camon, 2001). Consegue, muitas vezes, compreender o que sente. Sente-se acolhido, percebe que seu sofrimento é legítimo, que sim, ele tem o direito de sentir-se triste e que o choro pode lhe fazer bem.

\section{Conclusão}

O objetivo do presente trabalho foi exemplificar o fenômeno psicossomático no atendimento em prontosocorro, através da compreensão de casos atendidos. É possível constatar neste estudo que uma análise das falas dos pacientes adultos e idosos, confirma os dados encontrados na revisão da literatura sobre os aspectos psicossomáticos, ou seja, o orgânico influencia no psíquico e este no orgânico, pois ambos estão diretamente vinculados.

Este trabalho nos sugere que um grande número de pacientes, que poderíamos chamar de psicossomáticos, especialmente os idosos e as mulheres, são encontrados, diariamente, nos serviços de urgência e emergência dos hospitais, sobrecarregando ainda mais a demanda já existente neste tipo de setor, sem encontrar respostas eficazes para seu sofrimento/dor. Não adianta tratar apenas com remédios uma série de sintomas inespecíficos enquanto o verdadeiro problema se encontrar no inconsciente da pessoa (Spinelli, 2010). Eles geralmente freqüentam a Unidade de Emergência sem seguir um tratamento médico e/ou psicológico. Dessa forma, nos alerta Martins (2007), esses pacientes com transtornos psicossomáticos contribuem para elevar os custos e a demanda dos Serviços de Saúde. Se esses indivíduos fossem atendidos de acordo com suas necessidades individuais, as filas de espera poderiam diminuir e suas condições de saúde poderiam ser melhores.

O estudo também mostra a importância da escuta atenta ao paciente, pois tal escuta permite o acesso aos conteúdos latentes, traumáticos e inconscientes, que participam da manutenção dos sintomas físicos. Compreendendo esta ligação, os pacientes poderão modificar a forma como se relacionam com seu corpo 
e sua saúde. Assim, o corpo como canal de expressão dos sentimentos não precisa ser tão sobrecarregado e o indivíduo pode encontrar outras formas de expressão, como a expressão verbal.

Infelizmente, Ávila e Coelho (2007) chamam atenção para a falta de preparo de muitos profissionais da saúde para entender o paciente como um todo e acolhê-lo de uma maneira integral. Sendo assim, a atuação do psicólogo da saúde, referente à pacientes com características psicossomáticas, se faz necessária, uma vez que este profissional possui habilidade com as palavras e escuta qualificada. Seu trabalho no PS torna-se fundamental devido à grande demanda. A exteriorização de conteúdos somatizados facilita $\mathrm{o}$ alívio do sofrimento e melhora a qualidade de vida desses pacientes.

Portanto, apesar da prioridade do PS ser salvar vidas, defendemos o trabalho da psicologia dentro deste setor. O profissional acompanha o paciente no seu processo de adoecimento físico e psíquico, compreende seus medos, acolhe suas angústias, identifica as estratégias de enfrentamento utilizadas por ele, assim como os mecanismos de defesa que estão presentes.

Sendo assim, esse trabalho nos permitiu reafirmar as concepções de Simonetti (2009), que mostram que apesar do o Pronto-Socorro ser um local destinado a emergências médicas, ou seja, atende pessoas que se encontram em risco e precisam de atendimento imediato, após o problema médico ser resolvido, o psicólogo pode ser chamado a intervir, fazendo um atendimento de forma calma, tranquila, gerando um ritmo diferente do que é típico em um PS e acolhendo o paciente. Vimos, nos casos aqui discutidos, que muitos pacientes buscam o PS com queixas físicas decorrentes do adoecimento psíquico.

A evolução da concepção psicossomática e o reconhecimento do indivíduo como resultante dos fatores biopsicossociais reafirma o psicólogo como mais um profissional envolvido na busca da compreensão das doenças, permitindo uma abordagem mais humanizada do paciente, propiciando sua atuação no trabalho curativo e preventivo, aumentando as possibilidades e a qualidade nos atendimentos oferecidos aos pacientes em um setor de Pronto Atendimento. No entanto, considerando o exposto, também é importante que o trabalho da equipe de saúde seja interdisciplinar, por meio da escuta qualificada, a qual está além da humanização da instituição hospitalar, sendo essa, tarefa de todos os profissionais de saúde.

\section{Referências}

Angerami-Camon, V.A. (org.). (1988). Urgências psicológicas no Hospital. São Paulo: Pioneira, p 61-81.

Angerami-Camon, V. A. (Org.). (1998). Psicologia da saúde: um novo significado para a prática clínica. São Paulo: Pioneira.

Angerami-Camon, V.A. (org.). (2001). Psicossomática e a Psicologia da Dor. São Paulo: Pioneira.

Barros, J. A. C. (2002). Pensando o processo saúde doença: A que responde o modelo biomédico? Saúde e sociedade, Pernambuco, V. 11 n. 1, p. 67-84.

Casseto, S. J. (2004). Psicossomática e instituição hospitalar. In: Ferraz, F. C.;

Castro, M. G.; Andrade, T. M. R.; Muller, M. C. (2006). Conceito de mente e corpo através da história. Psicologia em estudo, Maringá, v. 11 n. 1, p. 39-43, jan./abr.

Chiattone, H. B. C. (2000). A significação da psicologia no contexto hospitalar. In:

Coelho, C. L. S.; Ávila, L. A. 2007). Controvérsias sobre a somatização. Revista de psiquiatria clinica, São Paulo, v. 34 n. 6 , p. 278-284.

Filho, J. M. (2005). Concepção psicossomática: Visão atual $\left(10^{\mathrm{a}} \mathrm{Ed}\right)$. São Paulo: Casa do Psicólogo.

Marco, M. A. (2003). A face humana da medicina: do modelo biomédico ao modelo biopsicossocial ( $1^{\mathrm{a}}$ ed.). São Paulo: Casa do Psicólogo.

Martins, V. A (2007). Psicossomática e transtornos de somatização: caracterização da demanda em um hospital escola no período de 1996 a 2004. Dissertação de Mestrado. Enfermagem Psiquiátrica. Escola de Enfermagem de Ribeirão Preto- USP - SP.

Moretto, M. L. (2001). O que pode um analista no hospital? São Paulo: Casa do Psicólogo.

Mutti, R.; Caregnato, R. C. A. (2006). Pesquisa qualitativa: análise de discurso versus análise de conteúdo. Texto \& Contexto Enfermagem, Florianópolis, v. 15, n. 4, p. 679-684.

Pacheco, C. B. S. (1994). A cura pela consciência (4a Ed.). São Paulo: Proton.

Romano, B. W. Princípios para a prática da psicologia clínica em hospitais. São Paulo: Casa do Psicólogo, 1999.

Simonetti. (2009). Manual de Psicologia Hospitalar: O mapa da doença. São Paulo: Casa do Psicólogo.

Spinelli, M. R. (2010). Introdução à psicossomática. São Paulo: Editora: Atheneu

Turato, E. R. (2000). Métodos Qualitativos na Pesquisa Científica - Revista Portuguesa De Psicossomática - v.2, n.1.

Yin, R.K. (1989). Case Study Research - Design and Methods. USA: Sage Publications Inc.

Recebido: 02/05/2012 Última Revisão: 04/07/2012 Aceite Final: 04/07/2012

Sobre os autores:

Alessandra da Rocha Arrais - Doutora em Psicologia; Docente do Curso de Graduação em Psicologia e do Mestrado em Gerontologia da Universidade Católica de Brasília. Psicóloga da Secretaria de Estado e Saúde do Distrito Federal. E-mail: arrais@ucb.br

Ana Paula Da Silva Vasques Oliveira - Psicóloga formada pela Universidade Católica de Brasília. E-mail: psi.paula.vasques@hotmail.com

Flora Teixeira Mota de Paula - Psicóloga formada pela Universidade Católica de Brasília. E-mail: floratmpaula@gmail.com 